\title{
When and Why of Mother Tongue Use in English Classrooms
}

Ashok Raj Khati

\begin{abstract}
It is often felt that teachers and students overuse their mother tongue, in this case, most probably the Nepali in English as a foreign language (EFL) classroom particularly in government-aided (Nepali medium) schools of Nepal. This, in result, minimizes the students' exposure to English. This article starts with defining mother tongue. Then, it presents the use of mother tongue in EFL classroom in the global and Nepalese contexts followed by summary of three classroom observations and two focused group discussions among teachers and students studying at the secondary level. The final part of the paper presents some simple and applicable strategies and ways of enhancing English language use in the classroom on the part of students provided by three teachers' trainers based on their experience.
\end{abstract}

Key words: Mother tongue, First language (LI), Second language (L2), English as a foreign language (EFL), Target language (TL)

\section{Introduction}

$\mathrm{N}$ epali serves as a lingua franca in education, mass media, administration, and in society in Nepal. Legally, it has been given the status of the official language. All three types of language situations monolingualism, bilingualism and multilingualism currently exist in Nepal (Giri, 2007). With reference to school level (that is, grades I to XII), almost half of the schools are English medium ones. In such schools, all subjects except Nepali are taught in English whereas, in government owned public schools, all subjects except English language are taught in Nepali language (Bhattarai, 2006).

It is sometimes difficult to distinguish the concepts of first language, native language, primary language, and mother tongue, although these are usually treated as a roughly synonymous set of terms. The distinctions are not always clear-cut. Defining mother tongue is always controversial and difficult (Buck, 2001). In general, a mother tongue can be defined as a language learnt before any other language has been learnt. So that a child learns mother tongue or first language automatically and naturally, he/she picks it up from the speakers and social environment around her/him. It has generally been said that the first language is learned at home during childhood i.e. language acquired from birth. But the cases are not always applicable in other contexts. For example, a child from Hayu community, one of the marginalized communities of Nepal, speaks Nepali as the first language but their mother tongue is Hayu, a language, which is believed to have its own distinct script (though not identified yet), phonological, syntactic and morphological systems. In addition, Hayu language lies under Tibeto-Burman language family. Though the population of Hayu community consists more than 1700 , the speakers of this language are enrolled only 68 in CBS report 2001.

The term 'mother tongue', 'first language' and 'native language/tongue' are essentially all the same though there are some instances when they mean different things. To conclude with Pokharel (2001) "first Language, mother tongue and native 
tongue are common terms for the language which a person acquires first in his childhood because it is spoken in the family and/or it is the language of the country where he is living (p. 201)." Therefore, the language that one first learns to speak when he or she is a child can be said the first language.

\section{Role of L1 in SLA literature}

It is a popular belief that second language acquisition (SLA) is strongly influenced by the learner's first language. The clearest support for this belief comes from 'foreign' accents in the second language (L2) speech of learners. When a Frenchman speaks English, his English sounds French. The learner's L1 also affects the other language levels-vocabulary and grammar. Another belief is that the role of L1 in SLA is negative one. That is, the L1 gets in the way or interferes with the learning of the L2, such that features of the L1 are transferred into the L2 (Ellis, 1985). There is still a controversy of using mother tongue or L1 in second language teaching learning. The use of L1 or mother tongue in English classroom has some advantages and disadvantages. It depends on when and what amount of first language is used in the EFL classroom. For example, Harmer (2009) points out that there are many occasions when using the students' L1 in the classroom has obvious advantages:

- If teachers want to discuss making a learning contact with their students, or to ask students what they want or need, then they will get more from lower-level students if they do it in the students' L1 than if they try to struggle through with English.

- Translation can also be a very good way of reviewing how well students have understood grammar and lexis at the end of a unit of study.

- Students (and their teachers) can use the L1 to keep the social atmosphere of the class in good repair.

At the same time, his serious objection to the use (especially the over-use) of the students' $\mathrm{L} 1$ is that it restricts the students' exposure to English.

The students' knowledge of their mother tongue is the greatest asset that they generally bring to the English language classroom. Dawson (2010) admits that teachers try to prevent their students from using L1 in the classroom, but they cannot prevent students from using L1 in their brains. The students' brain space is filled with their mother tongue that has formed the neural networks of their brains and their knowledge is in L1. They comprehend and process their thoughts in L1. Every journey starts from home. The linguistic journey into the foreign language also starts from home. He concludes that linguistic home, for the students, is their mother tongue.

The role of mother tongue also depends on the teaching methods a teacher applies in the classroom. Larsen-Freeman (2000) supports the role of the mother tongue in the classroom procedures and summarizes the role of L1 in various ELT methods. For example, a. Grammar Translation method: The meaning of the target language is made clear by translation into students' native language. b. Direct method and Audio-lingual method: The students' native language should not be used in the classroom because it is thought that it will interfere with the students' attempts to master the target language. c. Communicative Language Teaching: Judicious use of the students' native language is permitted in communicative language teaching.

To conclude with Ihara (1993) teachers would be required to be aware of when, how and why to use L1, that is to say, the proper use of L1 who denied that word-for-word and sentence-for-sentence translation. Many studies shows that limited use of mother tongue is beneficial and over use of it may counter-productive as it encourages the low exposure in target language.

\section{Role of L1 in different EFL contexts}

There are arguments regarding pros and cons of using the mother tongue in the classroom in the world of English language teaching. Several hundred years ago bilingual teaching was the 'norm', with students learning through translation. The use of L1 to study L2 was almost universal and readily accepted, in part because language teaching placed an emphasis on the written word above the spoken word. In the $19^{\text {th }}$ Century, this trend slowly reversed itself (towards a monolingual approach), in part due to a shift towards an emphasis on the spoken word. The impact of mass migration, colonialism and a large increase in research in the 
field would further strengthen the Monolingual Approach in the $20^{\text {th }}$ Century (Miles, 2004). After the innovation of communicative language teaching (CLT), there was very little use of mother tongue in English classroom.

Many professionals in the field of second language acquisition convict that L1 has facilitating role in learning second or foreign language classroom. At the same time, proponent of monolingual approach, Krashen (1981) has argued that people learning foreign languages follow the same route as they acquire their mother tongue, hence the use of the mother tongue in the learning process should be minimized. Tang (2002) affirms that during the last 15 years, however, monolingual orthodoxy has lost its appeal. Regarding the use of L1 Auerbach (1993) puts the views in this way that starting with the L1 provides a sense of security and validates the learners lived experiences allowing them to express themselves. The learner is then willing to experiment and takes risks with English. Schweers (1999) with the support of data suggests the limited and judicious use of L1 in English classroom who surveyed students and teachers at his Puerto Rican university and found that 88.7 percent of the students felt that Spanish (L1) should be used in their English classes. Eighty six percent of students felt that L1 should be used to explain difficult concepts and 67 percent said that L1 helps them to feel 'less lost'. Noticeable numbers of students responded on the following use for Spanish:

- to help them feel more comfortable and confident

- to check comprehension and

- to define new vocabulary items.

But neither student saw use of L1 in testing.

Mother tongue can be used to provide a quick and accurate translation of an English word that might take several minutes for the teacher to explain. Using English only, in EFL classrooms can lead to some problems because there would be no guarantee that the instructions and explanations are understood correctly. Hopkins (1988) claims that if the learner of a second language is encouraged to ignore his/her native language, he/ she might well feel identity threatened.
The issue of mother tongue use in EFL classroom was neglected and ignored in the past because it was readily accepted in second language learning contexts. The pros and cons did not seem to have been analyzed. But for last three decades there has been growing interest in studying the consequences of mother tongue use in English language classroom. Several studies have been carried on the issue mother tongue use. Atkinson (1987) lists the following appropriate uses for the L1 in L2 classroom: eliciting language, checking comprehension, giving complex instruction to basic levels, using translation to highlight a recently taught language item, checking for sense, testing and developing circumlocution strategies. Likewise, Auerbach (1993) identifies the following uses for mother tongue: classroom management, language analysis, presenting rules that govern grammar, discussing cross-cultural issues, giving instructions or prompts explaining errors, and checking for comprehension. In comparing the study of Schweers, Tang (2002) has claimed that both studies indicate that the mother tongue was used by the majority of teachers responded positively toward its use. In her study, sixty-nine percent students felt that mother tongue should be used to understand the difficult concepts better. Miles (2004) conducted two different experiments that showed that L1 use helped to foster confidence and where L1 was utilized, the students showed a significantly higher improvement in the area of speaking. The findings of both experiments support that L1 use in the English classroom does not hinder the leaning rather it can actually facilitate it.

Several studies show a general agreement on the moderate use of mother tongue in L2 learning. It seems that L1 provides a sense of confidence on the part of students. No studies recommend the unnecessary use of L1 in L2 classes however; it also depends on the teaching methods a teacher applies in the second language learning.

\section{Use of mother tongue in English classroom in Nepal}

In the context of Nepal, excessive use of Nepali language can be observed in schools, it is felt that the main reason behind this maximum use of mother tongue is the low exposure on the part of 
students in English language. In this light, Rana (2009) puts his views as follows:

Except in certain English medium schools, the students hardly have enough exposure to English language- only 5, 6 hours of classes a week. This is not sufficient for several reasons. They have quite less access to other audio video exposure and hardly enough time and room for language performance in the schools. In remote localities, the situation is even worse. If the language teacher fails to be a good resource, it will be one of the worst (p. 87).

Bhattarai (2001 cited in Luitel 2005) states that in a 45 minutes class period more than $80 \%$ hours are consumed by Nepali language in the schools. Teachers in remote localities have quite less access to other audio-video exposure. Even if a lesson is meant for involving the learners in practical conversation through English, teachers tend to present the lesson employing the L2L1 translation method (Tripathee, 2001 cited in Luitel, 2005). Proficiency level of students also plays role in use of mother tongue. In this light, Luitel (2005) investigated that among the learners of lower strata, who were poorer in word meaning knowledge, there is the clear indication that the use of translation has brought about significantly better result in productive vocabulary knowledge. Similarly, the excessive use of mother tongue might have facilitated the learners' understanding but it has hindered their progress in developing productive competence (Khanal, 2004). In fact, the situation has been serious that teachers and students consume eighty percent (80\%) hours using mother tongue (most likely the Nepali) in the classroom especially in under-resourced part and government-funded schools in Nepal. However, the English language use in certain English medium schools and colleges is satisfactory as the medium of instruction is English there to teach all courses except Nepali language.

Regarding in the context of Nepal, Khanal (2004) concluded that moderate and judicious use of mother tongue (Nepali) aids the learning and teaching of the target language. The teachers (informants in the study) think that it is necessary to use Nepali in the English classroom to explain difficult concepts or ideas, to practice the use of some phrases and expressions and to present complex grammar points. In the same way, the students use the Nepali language in English classroom to explain their own problems and if they don't know the answers. Similarly, some students use Nepali to ask questions and to give answers. The study shows that learners' weaknesses and their poor background are responsible factors for using the Nepali language in the English classroom. In his study, Sharma (2006) finds out that sixty-four (64\%) of students realize that Nepali should be used to define new vocabulary items. More than half of the students think L1 should be used to explain grammar points, difficult concepts or ideas and, to practice the use of some phrases and expressions. This study also showed that students from the government-aided school feel more need of their mother tongue than from the students of private boarding school. He further suggests the limited and judicious use of mother tongue and points out that the teacher should be very selective on when to use and when not to use. It shows that Nepalese English classes are more focused on reading and writing skills and teacher get help of Nepali for difficult ideas, new words and grammar points. Though teachers and students, they opine in favor of limited use of mother tongue, the reality is different in the classrooms.

Ramechhap district, for example, from where this researcher has obtained data, has a few English medium institutions in this district though some government-aided schools have recently made effort to make the English as the medium of instruction from primary level. According to the census report (2001), 13 identified languages are spoken in this district. 56.59 percent people speak Nepali language as their mother tongue in this district. It is observed that students with other native tongues except Nepali rarely use their mother tongue inside schools. Most of the time, they use Nepali with their friends and teachers inside and outside classroom. Children, for example from Hayu, Pahari, Majhi and many other marginalized communities, are often seem to have forgotten their mother tongues because of the dominant role of Nepali language in every sectors and their parents' reluctance to use their own mother tongue. 


\section{The study}

The issue of mother tongue in EFL contexts has been a major debate whether to use mother tongue or only target language. This study tries to answer three main questions a) how frequently and on what occasions do the teachers at secondary level use mother tongue (i. e. Nepali)? b) Why do the students use mother tongue in English classes? c) How can one reduce the over-use of mother tongue in English classes? To obtain responses to aforementioned questions: (a) three classrooms of English teachers teaching at secondary level were observed and for question (b) two focused group discussions were conducted with ten students and ten teachers of same level and whereas to obtain the answer of last (c) question three experienced English language teachers' trainers were interviewed who have been training teachers for last fifteen years.

\section{Classroom observation}

Three separate classrooms were observed for an hour in different schools, i.e. three lessons. The lessons were recorded using diary. The researcher was accompanied by his colleague to take notes of the lessons.

\section{Findings}

Shiela was teaching a story and seemed to be attentive while presenting the lesson though she was not informed about the purpose and nature of study. It was the lesson of grade nine. She used Nepali language four times to make fun with the students, which seemed to be an effort to make them confident but she tried to explain a few words ardent, simultaneously, flutter, disappointment and distress in English. Students also responded to her in English. She used Nepali once to make clear about the concepts of 'angles'.
Daman was teaching a reading text about Nepalese festivals at the tenth grade. It was the lesson at government-aided (Nepali medium) school. He used Nepali seven times to explain the words pace, ancestors, priest, flavour, circle, rituals, and dilemma. Likewise, he used Nepali ten times to give classroom instruction but used it two times to make fun with the students. His students rarely used English in the classroom except yes or no type of responses. He used Nepali twice to make the students feel confident and easy, whereas the greatest number he used Nepali were eleven times to make some concepts clear which seemed to be difficult for students. Those were: religious rituals, successful marriage, cursing their fate, reflecting their mixed emotions, forceful current of river, dazzling ornaments, worshipping their ancestors, reflecting their simple life, a bearded character, cultural richness and filling the tranquil night air.

Ramesh was teaching a grammar lesson at government-aided (Nepali medium) school. It was a lesson of grade nine in which he used Nepali five times to explain grammar points. He used Nepali most frequently to give instructions. Those were ten instances to make clear what was said. Likewise, he translated the word path in Nepali. At the beginning he tried to make the students feel easy using Nepali two times when he talked about 'weather' and 'classroom envornment'. In the middle of the lesson, he used Nepali two times to confirm their responses: ho ra? (is it?) and ke yo hoina ra?(isn't it?).

Table 1 shows the summary of the frequency and occasions that the teachers used Nepal in an hour minute English classes:

Table 1: Classroom observation results

\begin{tabular}{|c|c|c|c|c|}
\hline Occasions & Freque & using $\mathrm{Nep}$ & eachers) & \\
\hline & Sheila & Daman & Ramesh & Total \\
\hline To give instructions & & 9 & 10 & 19 \\
\hline To make difficult concepts clear & 1 & 11 & & 12 \\
\hline To explain new words & & 7 & 1 & 8 \\
\hline To make fun & 4 & 2 & & 6 \\
\hline to explain grammar points & & & 5 & 5 \\
\hline To make students' feel confidents & & 2 & 2 & 4 \\
\hline To confirm students' responses & & & 2 & 2 \\
\hline
\end{tabular}




\section{Focused group discussion}

Ten students studying at the secondary level and ten teachers teaching at the same level of Nepali medium school were selected purposively from Ramechhap district to elicit their views from two focus group discussion. Their responses were recorded using notes, and I took help of my colleague to trace their views in his diary too. In the process of data collection, students were allowed to express their views in Nepali as well. Thus, a few quotes are edited and translated in English while summarizing.

\section{Teachers' views}

Majority of reasons given by the teachers show the real situation of EFL classroom in Nepalese scenario, primarily of Nepali medium large classroom. Students' inhibition in speaking has seemed to be a major reason for using Nepali in English classroom.

Toran: Many students hesitate to speak in English due to pronunciation difficulties, fear of criticisms or losing face in the classroom and other students laugh at them while they start speaking English.

Some students also found hesitated because of the fear of teachers' punishment and negative comments if they commit errors particularly in verbal communication.

In Nepalese context, students make frequent use of Nepali in large classes with mixed abilities.

Khadga: Few students think they can bypass speaking in large classrooms, furthermore, they think, it is high achievers' job to communicate with teachers in English. We (teachers) cannot give individual attention toward students in large classes and not every student gets sufficient opportunities to use English in such classes.

A teacher finds the role of other members in a student's group a major reason of mother tongue use:

Mina: Some students even feel inferior among friends to use English and, some of them find their friend always using mother tongue, hence they do not find themselves encouraged by their friends. This perhaps makes a few curious students neglect in using English.

Amongst all teachers, there was general agreement that students in government-aided schools find Nepali easier to use:

Lilita: L1 is already equipped in their (students') mind, they find easy and comfort in using Nepali.

A few teachers also notice themselves (teachers) the reason of excessive use of Nepali, simply because they do not make the students use English compulsorily and students do not think it is necessary to use English. Moreover, a teacher viewed that they themselves use L1 in classroom and are not frank enough with students; as a result, students are found reserved.

One of comment of a teacher shows that it is sometime really challenging to teach grammatical points and some abstract concepts without using Nepali, and they use it to make those grammatical rules and difficult concepts clear. In this case, following teacher's view is entirely different from that of others. He places his emphasis on the students' own personality to practise using English:

Milan: Students' own personalities also influence in using English particularly in speaking, some students are introvert, less sociable. They do not make any effort to talk in English; I think they are learning English simply because it is in curriculum. It shows the negative attitude toward English language learning.

\section{Students' views}

There are some points made by the students, which are similar with teachers. Majority of them agreed that they use Nepali because they cannot pronounce many words in English even if they are familiar with the meanings of the words; additionally, they stated that their friends usually laugh at them while they are speaking English. It indicates that to speak English is to be superior to others inside the classroom. A student put a similar view with what a teacher mentioned that he is afraid of teachers' negative comments if he commits an error. Of course, students do not commit any errors in their mother tongue to communicate with English teacher. Similarly, lack of sufficient practice in target language is another reason of frequent use of Nepali: 
Chetan: My English teacher only encourages high achievers to use English in the classroom so that low achievers do not get enough opportunities for oral practice. We just listen to those high achievers and teacher who are at the front of the classroom. There are many occasions when we just copy whatever the high achievers speak or write in the classes. Ninety-percent of time, I use Nepali with my friends at back row, but teacher does take no notice of it.

A student mentioned that she does not know what she will do with English while another viewed that it is very easy to use Nepali. It is also revealed that even if they can use some common communicative functions in English in the classroom, students use Nepali for no reasons but easy means. At the same time, there are some occasions when students do not understand in TL:

Maniram: I did not understand what my teacher shared with us to teach a few passive structures and use of causative verbs in previous day. The next day I requested him to explain in Nepali, and then I could get some ideas and started practicing more examples. So it is very difficult to grasp grammatical points without using Nepali.

One of the most strongly articulated reasons of using Nepali, in approximately half of the group, was English teachers' preference of choosing Nepali as they do not make any effort to enhance English language use. A good example, found in the following comment:

Sarita: I use Nepali inside the classroom among friends though I wish I could use English fluently. Tara, ke garne? (But, what can we do?) Our English teacher never makes us use English, neither he encourages competition in English, nor he himself uses English.

In fact, she finds greater role of English teacher to minimize the use of mother tongue and enhance target language use.

\section{Interviews}

Three teachers' trainers were interviewed to share their experiences on how one can enhance the target language use i. e. English for the beginners and pre-intermediate level students who have low exposure in English. It was a semi-structured interview and their opinions were recorded by using notes.

\section{Background to trainers}

At the time of study, Prakash is in his 25th year of teaching and training the primary and secondary level teachers. Gopinath has 16 years teaching experiences at the commencement of this study. He has been training the primary level teachers for ten years. Chandra, at the time of the study, was in his 18th year of teaching English and he has 12 years teacher training experience at school level.

\section{Enhancing English language use}

Prakash laid emphasis on the use of various 'topics' in the classroom:

First of all, we can use a variety of 'topics' in the classroom to maximize English language use of students' varied interests either at the beginning or middle or at the end of the lesson period." In this respect, teacher can initiate talk on 'topics' like feast days and holidays, thing students did the previous days, a piece of local news, a local sport events, a school performance, interesting TV programme etc. He goes on to describe as follows: "these 'topics' not only create English language atmosphere in the classroom, but also help students to feel relaxed and minimize the use of Nepali.

His views indicate that instead of going straight to the textbook at the beginning of a lesson the teacher can spend a few minutes 'chatting' to the class about topics of interest (Doff, 1988).

He goes on explaining as follows:

We should give positive feedback to avoid their hesitation most probably in oral communication because the students are often worried about making errors because of the fear of losing face among friends.

In such case, teacher can apply the strategy to approve their minor errors as frequent and immediate correction pesters students using target language particularly in verbal communication. At the same time, he or she may appreciate target language and acquaint them with the value of it which obviously will create positive attitude toward English.

Gopinath indicates the inevitable role of 
classroom language functions to maximize the exposure in English:

I think, one of the possible ways to enhance English use is to prepare students to make use of necessary classroom language functions (for instance, greeting, introducing, requesting, begging apology etc) at earliest. Teacher should keep speaking English most of the time which will give the students practice in listening and responding to spoken English as well as it helps to 'pick up' words and expressions beyond the language of the text book.

There's no doubt that, in the classroom, using shorter and simpler expressions could make them understand and imitate easily rather than longer and complex ones on the part of teachers.

Gopinath further states on about of the role of English teacher to minimize mother tongue use:

Students do not make use of English if they think it is not necessary to use it. Some English teachers found success by making students to use English compulsorily. While others give the lesson contests like nature for the activities in speaking, reading, writing and others where the supportive and encouraging role of a teacher is must.

Chandra points out the use of English as opportunities in different stages of a lesson on the part of teacher:

In my opinion, teacher can exploit various 'opportunities' as much as possible to boost up English language use in a class period. For example, he or she may use simple expressions while greeting, organizing classroom, checking attendance, introducing the lesson, presenting new language, words or structures, moving from one activities to another, setting pair work and group work, setting and marking homework, asking questions related to the texts, and ending the lessons.

He further adds that many English teachers even if they know to utilize these prospects, they do not make effort to use English simply because they find it easier to use Nepali. He concludes with following view:

If a teacher makes the best use of these opportunities, students will be prepared for need of more English.
In sum, there were mixed views on how one can enhance English language use. Table 2 shows the summary of strategies for enhancing the TL use:

Table 2: Strategies for enchaining TL use

\begin{tabular}{|l|l|}
\hline \multicolumn{1}{|c|}{ Trainers } & \multicolumn{1}{|c|}{ Strategies and activities } \\
\hline Prakash & $\begin{array}{l}\text {-Use of 'Topics' } \\
\text {-Creating positive attitude toward L2 } \\
\text { learning }\end{array}$ \\
\hline Gopinath & $\begin{array}{l}\text {-Training students in classroom language } \\
\text { functions } \\
\text {-Supportive role of teacher }\end{array}$ \\
\hline Chandra & $\begin{array}{l}\text {-Use of 'Opportunities' } \\
\text { (use of English in various stages of a les- } \\
\text { son) }\end{array}$ \\
\hline
\end{tabular}

\section{Discussion}

The study shows many similarities to Sharma's (2006) and Khanal's (2004) studies at Nepalese context regarding the use of mother tongue in English classroom. For example learners' from government-aided school with their poor background feel more need of L1. Another similarity between these three studies is that teachers generally use Nepali to explain difficult concepts, grammar rules, new words and they use it to give instructions though the frequencies in using it to some extent differs from one to others. It also shows that like Schweers's (1999) and Auerbach's (1993) studies, teachers use Nepali language to make students feel comfortable and confident inside classroom. The teachers and students from private schools do not seem to have found using Nepali so frequently. However in this study, a new fact is clearly revealed that teachers and students enjoy making fun and telling jokes in Nepali in Nepalese context. Another difference in this study is its focus on the use of mother tongue in an English classroom of government-aided schools at rural ELT setting of Nepal.

This study not only tries to find out when mother tongue is used but also why it is used in EFL classroom which shows that teachers and students use mother tongue for number of reasons. They agreed that the primary reason for using L1 is the inhibition in speaking due to pronunciation difficulty and fear of losing face in the classroom on the part of students. Secondly, students find lacking sufficient oral practice in English in the classroom because of large class size, uneven 
participation of students and teachers' focus on writing skills. The other reasons provided by students and teachers are: L1 intervention, complex ideas, lack of teachers' effort, students' own personality, negative attitude toward L2, negative feedback from the side of teachers. The study emphasizes on the supportive of teachers to enhance TL use in a classroom where students have poor background in English. This study is also different with other studies in the sense that it attempts to seek some applicable strategies and activities to reduce mother tongue use (over use) in EFL classes. The study clearly shows that use of 'topics' can be useful to make the students feel comfortable and positive feedback will definitely encourage students to use English without hesitation. Likewise, training students in classroom language functions have greater role in enhancing English use for beginners. At the same time the study has revealed that using shorter and simpler expressions in English at different stages of a lesson certainly fill the gap of using Nepali.

\section{Conclusion}

Nepali serves as a lingua franca among different multilingual speakers of Nepal. As a result, many students share Nepali language inside the classroom though they are from diverse linguistic backgrounds. Even if it is sometimes very hard to define the mother tongue or L1 the language one learns first when he or she is child can be termed as first language. It is agreed that knowledge of L1 is the students' greatest asset that they bring to English language classroom. Preventing them from using it is to prevent them from great neural process of comprehension and thought. There are, of course, pros and cons regarding the use of mother tongue, it depends on when and what amount of first language is used in the EFL classes. Nevertheless, many studies support the limited and occasional use of it. No studies recommend the excessive use of mother tongue as it hinders the exposure in target language.

In the context of Nepal, maximum use of Nepali can be observed in Nepali medium schools mainly in under-resourced parts and the studies carried out at Nepalese ELT setting also shows that students with low language proficiency at government funded schools feel more need of Nepali than the students from private English medium schools.
They use it due to shyness in speaking in a large class. And sometime they cannot express the complex ideas in English. The study suggests that through meaningful oral practice in English, using shorter and simpler expressions, short chatting in English with students, training students on necessary classroom language functions and encouraging role of teachers, of course, may enhance target language use. Most importantly, teacher should keep speaking English to maximize the exposure of students in English language.

\section{The Author}

Ashok Raj Khati has been associated with English language teaching at tertiary level for about a half decade. Currently, he works at Gauri Shankar Multiple Campus, Ramechhap affiliated with Tribhuvan University Nepal. Mr. Khati is a central committee member of Nepal English Language Teachers' Association (NELTA) and an advisor of NELTA Ramechhap Branch. He has travelled throughout the country as a paper presenter. He also attended the International Visitor Leadership Program (IVLP), for about a month under the theme teaching English as the second language (TESL) in the United States in 2011 . He has keen interest in psychology in language learning, English language pedagogy and teacher development.

\section{References}

Auerbach, E. (1993). Reexaming English only in the ESL classroom. TESOL Quarterly, 27 (1), 9-32.

Atkinson, D. (1987). The mother tongue in the classroom: A neglected resource? ETL Journal, 41 (4), 241-247.

Bhattarai, G. R. (2006). English teaching situation in Nepal: elaboration of the theme for panel discussion in the $40^{\text {th }}$ TESOL conference. Journal of NELTA, 11 (1-2), 11-16.

Buck, G. (2001). Assessing listening. Cambridge: CUP. Central Bureau of Statistics. (2001). Population Census (2001). Kathmandu: Central Bureau of Statistics.

Dawson, N. (2010). L1 in the EFL classroom: The truth. Retrived on 16th June. 2011 from:http:// www. iatel.britishcouncil.org/sessions/2010/11efl-classroom-truth

Ellis, R. (1985). Understanding second language acquisition. New York: OUP.

Giri, R. A. (2009). The politics of 'unplanning' of languages in Nepal. Journal of NELTA 14, (1 \&2) 32-44. 
Harmer, J. (2008). The practice of English language teaching. Pearson: Longman.

Hopkins, S. (1988). Use of mother tongue in teaching of English as a second language to adults. Language Issues, 2, 2, pp. 18-24.

Ihara, T. (1993). On the use of mother tongue in the English language classroom. Retrieved on $21^{\text {st }}$ August. 2011 from:https://soar-ir.shinshu-u. ac.jp/dspace/handle/10091/1629

Khanal, K. (2004). A study on the use of Nepali language in English classroom. An unpublished M.Ed. Thesis. Kathmandu: Tribhuvan University.

Krashen, S. (1981). Second Language acquisition and second language learning. Oxford: Pergamon.

Larsen-Freeman, D. (2000). Techniques and principles in language teaching. New York: OUP.

Luitel, B. (2005). Role of translation versus nontranslation tasks in productive vocabulary development: empirical evidences. Journal of NELTA, 10 (1\&2), 45-56.

Miles, R. (2004). Evaluating the use of L1 in the English language classroom. An unpublished M. A. thesis. Department of English. University of Birmingham, UK.

Pokharel, B. R. (2001). Applied linguistics. Kathmandu: Jupiter publishers and Distributors.

Rana, T. S. (2009). ELT situation at our schools and we. Journal of NELTA Syangja (1), 87-91.

Schweers, W. Jr. (1999). Using L1 in the L2 classroom. English Teaching Forum, 37 (2), 6-9.

Sharma, B. K. (2006). Mother tongue use in English classroom. Journal of NELTA, 11 (1\&2), 80-87.

Tang, J. (2002). Using L1 in the English classroom. English Teaching Forum, 40 (1), 36-43. 